\title{
Web Based E-Hospital Management System
}

\author{
Ridhab Sami Abd-Ali ${ }^{1}$, Salih Mahdi Al-Qaraawi², and Muayad Sadik Croock ${ }^{3}$ \\ 1,2,3 Computer Engineering Department, University of Technology, Baghdad, Iraq \\ 1'ce.120086@uotechnology.edu.iq, ${ }^{2} a l \_q a r a a w i 55 @ y a h o o . c o m,{ }^{3}$ muayadkrook@yahoo.com
}

\begin{abstract}
Hospital Management System (HMS) is a computerizing scheme used to simplify several efforts of the working in a hospital. The system deals with all the requirements of different hospitals to offer efficient services to patients. In addition, it stores the patients' information for long term for historical records. In this paper, we design and implement a web based HMS for group of hospitals in Iraq. The system provides an efficient link between the hospital's departments including the laboratories, radiology, pharmacy and the consultants. The proposed system gives simple access to basic data, thus enabling the management to take better decisions on time. The website is designed using PHP, HTML and CSS environments, while the database is built utilizing MySQL version 5.7.11. As a case study, two hospitals (Margan in Babylon and Ibn-Alnafees in Baghdad) have been considered. The results show that the proposed system has achieved high performance and accuracy in terms of provided health services, data management and time consuming.
\end{abstract}

Keywords: - Hospital Management System, health care, Database, webpage design.

\section{INTRODUCTION}

The Health Management System (HMS) is important to manage the health organizations in viably and effectively way. Previously, it was hard to keep proper records of the real-time activities of hospitals, patient data, and supported equipment [1]. A huge amount of efforts have to be performed inside the hospital for administration affairs in addition to health services, such as paper work, doctors' reminding messages, available medicines, and correct diagnosis [2], [3]. By enabling a computerized, automation and intelligent stream of patient data, the HMS enables hospitals and doctors to provide a high quality service for their patients. Furthermore, the HMS introduces a large group of direct advantages, for example, easing patient record management, reducing paperwork, fasting data stream between different departments, providing organizational flexibility, reducing wastage, decreasing waiting time at the counters for patients and degrading registration time for patients [4].

In the current system no real time access to patient's history, this results in inconvenience and wastage of time. Moreover, not possible to manage drugs inventory. There is delays in immediate storage of data generated by various transactions. In addition, doctors have to remember various medicines available and sometimes cannot remember them at that time. Lack of prompt updating. Also, calculation of patient's bill take a lot of time this may result in incorrect information. There are a lot of deaths from incorrect prescriptions because of large number of papers and the omission of the pharmacist.

\section{RELATED WORK}

In literature review of the related research work, numerous papers have been introduced to manage and improve the health services in hospitals. In [5], the authors supposed that the healthcare needed to be easy technique, modern and efficient. This to make professionals and patients are more reliable to be used in assisting of using multimedia, such as speech, text, images and videos. In [6], the authors 
constructed an integrated Hospital Information System (HIS) by deploying information technologies. These technologies include a range of techniques, such as patient registration systems, inpatient management systems, laboratories, patient billing, out patient management systems, pharmacy management, patient appointment management, human resource management and nursing care management. These techniques helped the medical professional to improve the quality of services, patient care, easy and quick access to important information and performs complex tasks that involve of tabulating, retrieving, account, printing and security of data. In [7], the authors proposed an electronic hospital information system that has the ability to create a database of patients. This played a main role in data analysis and to facilitate decision-making concerning the patients in addition to reducing the cost and the time. There were several barriers appeared during system implementation, the human and financial obstacles are the reasons and the main categories of barriers against the evolution of Electronic medical record [8].

In this paper, an efficient web based e-hospital management system is introduced. The proposed system offers the health services and information for patients and staff in easy manner. It includes two main parts: web based sites and relational database. The web pages providing visual services to users for easy dealing with the system. While the database is connected with the related webpages to store the information of medicines, tests and consultations. The proposed system has been tested over different case studies for two hospitals in Iraq. The obtained results show the superior performance in terms of management and health services providing.

\section{THE PROPOSED ALGORITHM}

The provided e-hospital system is adopted a proposed algorithm for managing all departments of such hospital. Each department has its own sub-algorithm for dealing with the information concerning the patients and doctors as well as the staff. Fig. (1)-(9) explain the flowchart of the proposed subalgorithm for each department represented as a webpage. The work of the proposed algorithm can be summarized in the following list of points:

1- At the arriving of a patient to hospital, the patient goes to the patient registration section. In case of the patient attend for the first time, the registration employee asks for the required information of the patient for registration and generating a new record of unique ID.

2- If the patient is already registered, then the employee uses patient ID or patient name for searching his/her information.

3- The patient is sent to the billing system for paying the consultation fees. Fig. (1), illustrate the three above steps. Then the patient can see the consultant after passing through the steps of billing system shown in Fig. (2).

4- In case of the doctor asks for some tests from the laboratories, he/she can just tick on the required tests and consider the payment process according to the hospital policy as shown in Fig. (3). If the tests are free then the system send them directly to the laboratory. Otherwise, the patient must go to the billing system and then to laboratories. After the tests are completed, the results will send back to the doctor following the working steps of Fig. (4).

5- At the other hand, if the doctor wants to send the patient to the radiology, he / she can select the required test by clicking one or more of x-ray, CT-scan and mammography as shown in Fig. (2). Later, the system determines they are free or paid according to the hospital policy. If the radiology tests are free then the system sends the patient to the radiology section, else the patient must go for billing affairs and then back to radiology section. The results are also sent back to the doctor as shown in Fig. (5).

6- The doctor write prescription to the patient passing through the billing system then to the pharmacy that is working based on the sub-algorithm shown in Fig. (6). When a medicine in pharmacy has 
quantity less than $20 \%$ of maximum quantity, the pharmacy sends an order to specific warehouse as explained in Fig.(6). The pharmacy also have issuing drugs process that is working statistically to show the amount of issued drugs for the hospital through week, month and year. Therefore, it helps the pharmacy and warehouse to know amount of drugs needed as average.

7- If the doctor finds out that the patient must stay in the hospital, then he/ she checks if there is available bed in this hospital and sends the request to the Inpatient Department (IPD). Otherwise the patient can be sent to another hospital. The IPD gives for the patient ward number, room number and bed number following the procedure steps of Fig. (7). When the patient is discharged, the billing system charges him/her the required fees by the IPD.

8- The warehouse of drugs receives the orders from pharmacies and responds them by sending all the quantity required by the pharmacy if available or part of the quantity and later sends another part when available as explained in Fig. (8). It is important to note that most of the action done by the warehouse are the same to the pharmacy, such as adding medicine, .., etc. Therefore, we focus in the flowchart on the new action of responding the orders.

9- The staff registration is explained in Fig. (9).

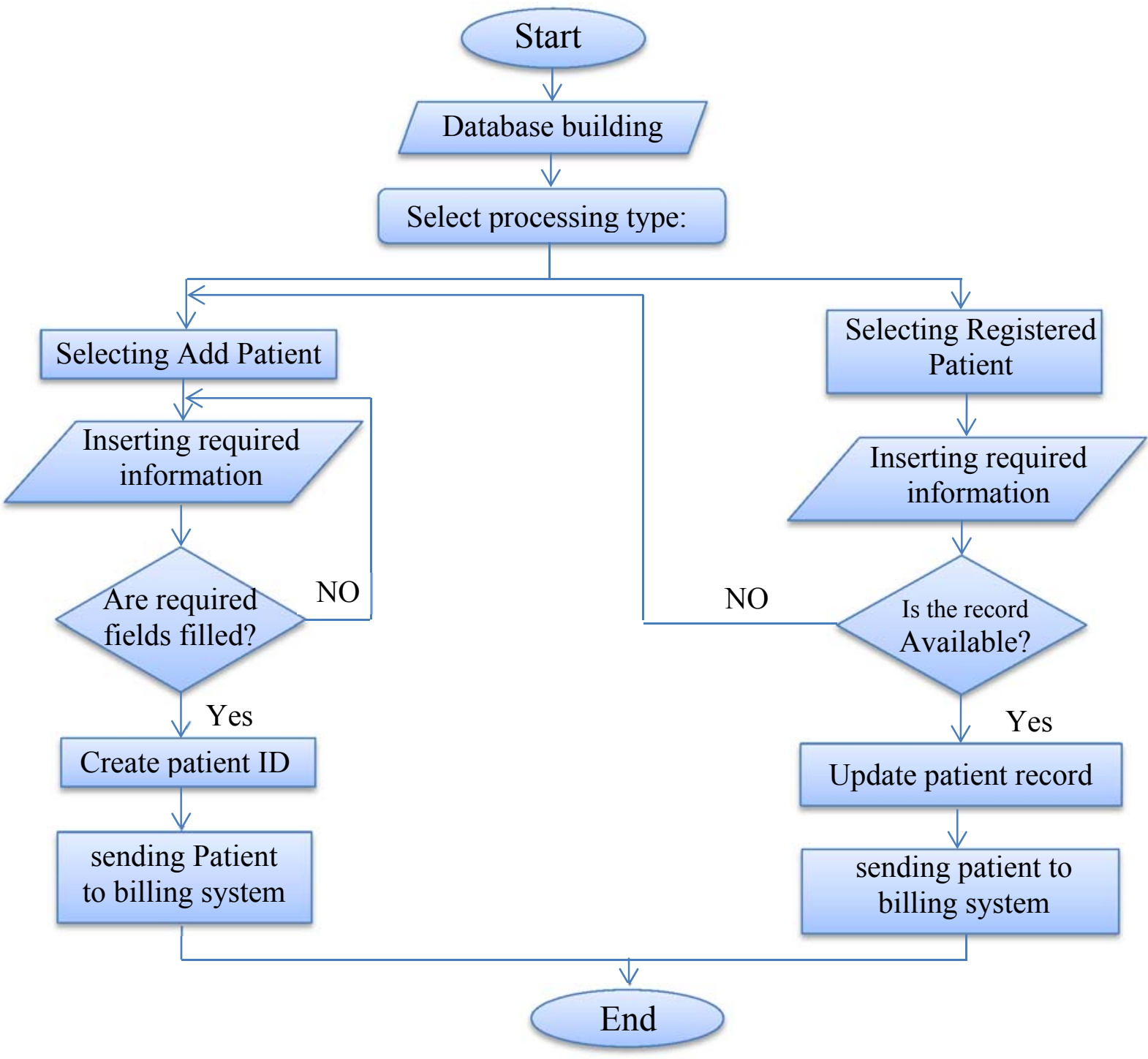

FIG. (1): FLOWCHART OF THE PATIENT REGISTRATION PAGE. 


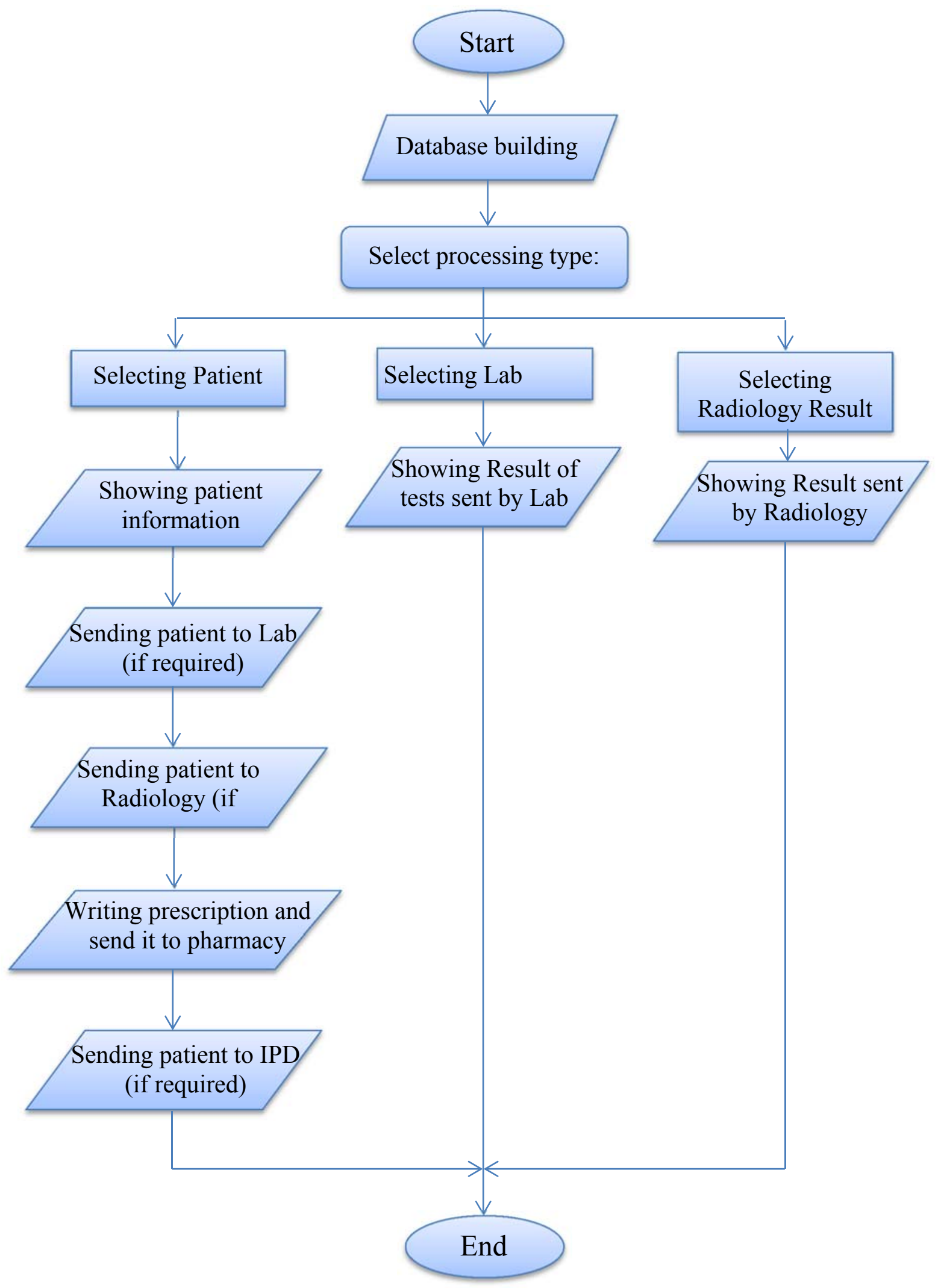

FIG. (2): FLOWCHART OF THE DOCTOR PAGE. 


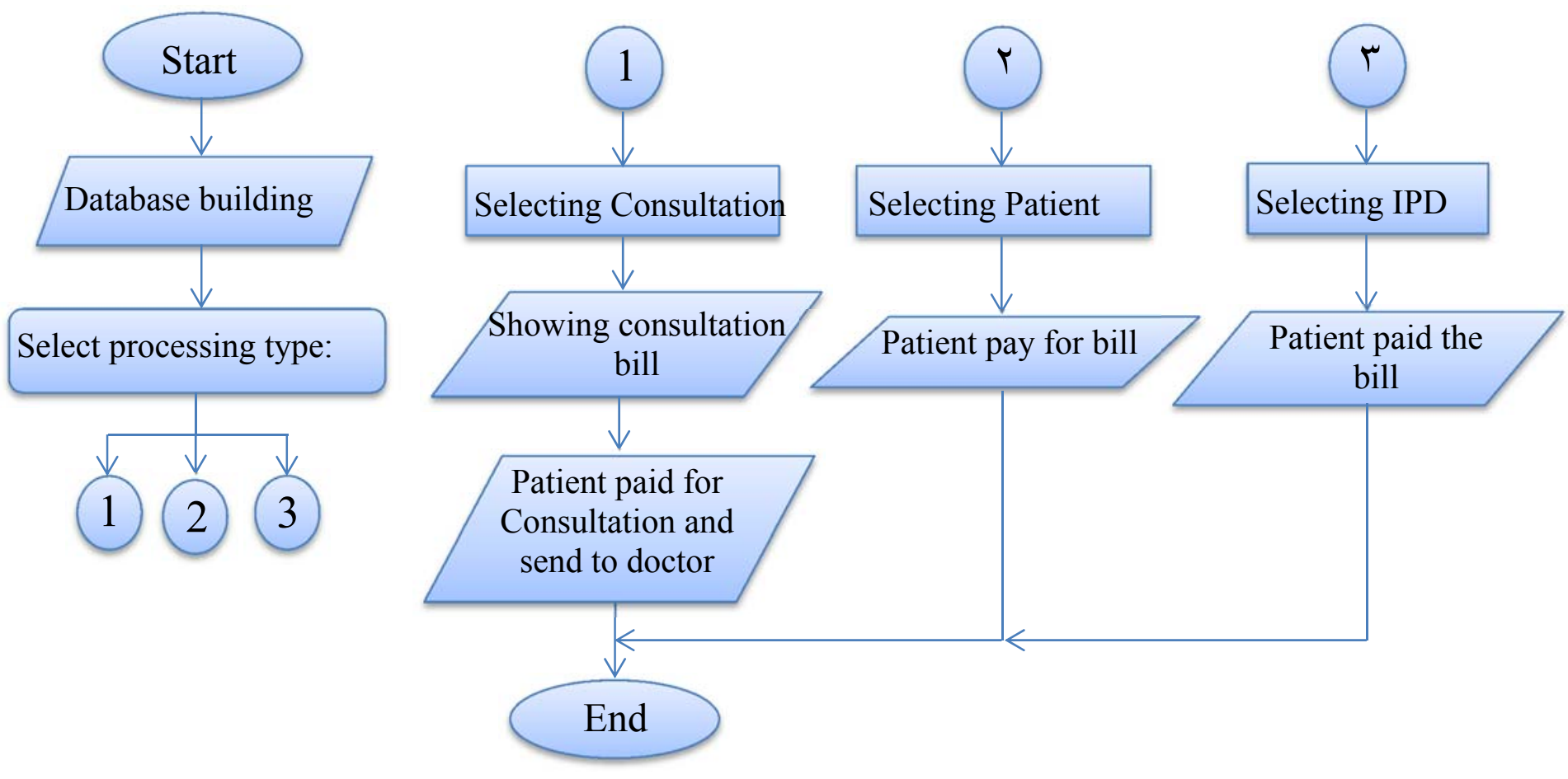

FIG. (3): FLOWCHART OF BILLING SYSTEM PAGE

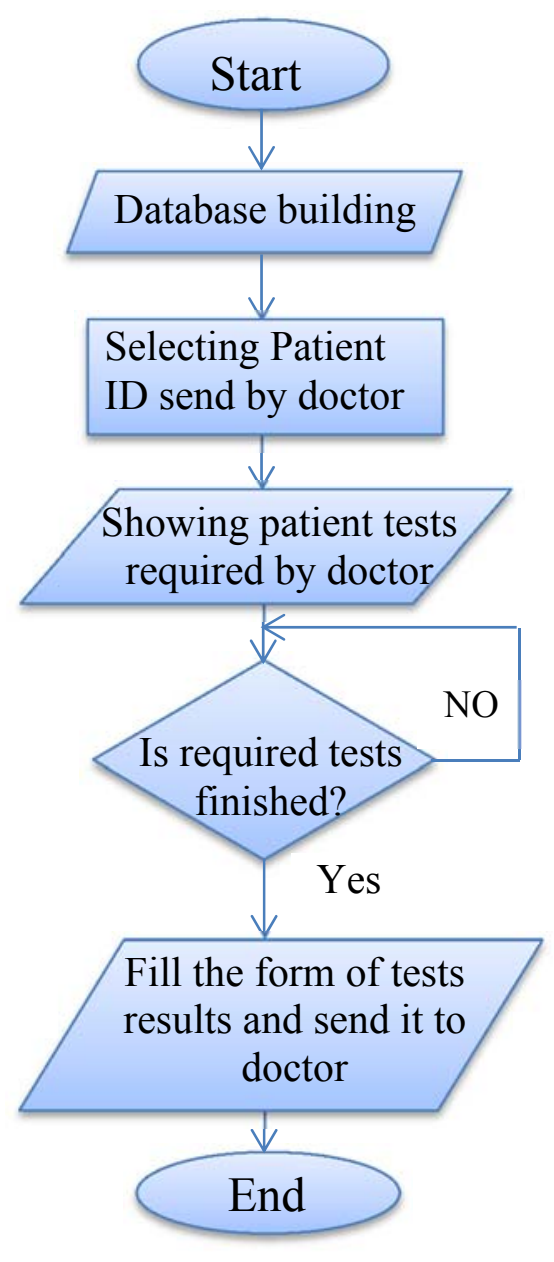

FIG. (4): FLOWCHART OF THE LAB PAGE

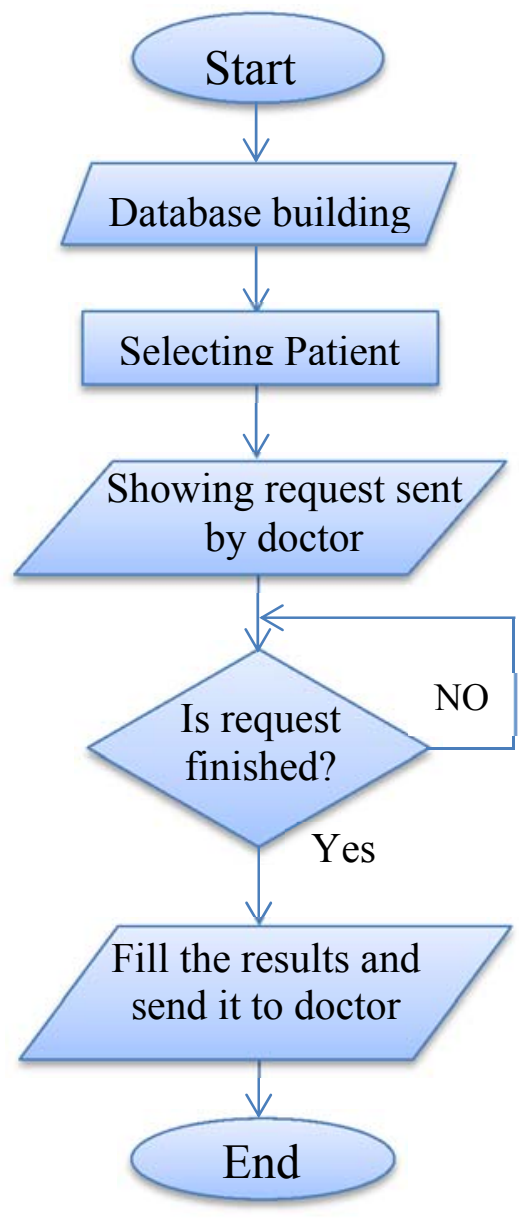

FIG. (5): FLOWCHART OF THE RADIOLOGY PAGE 


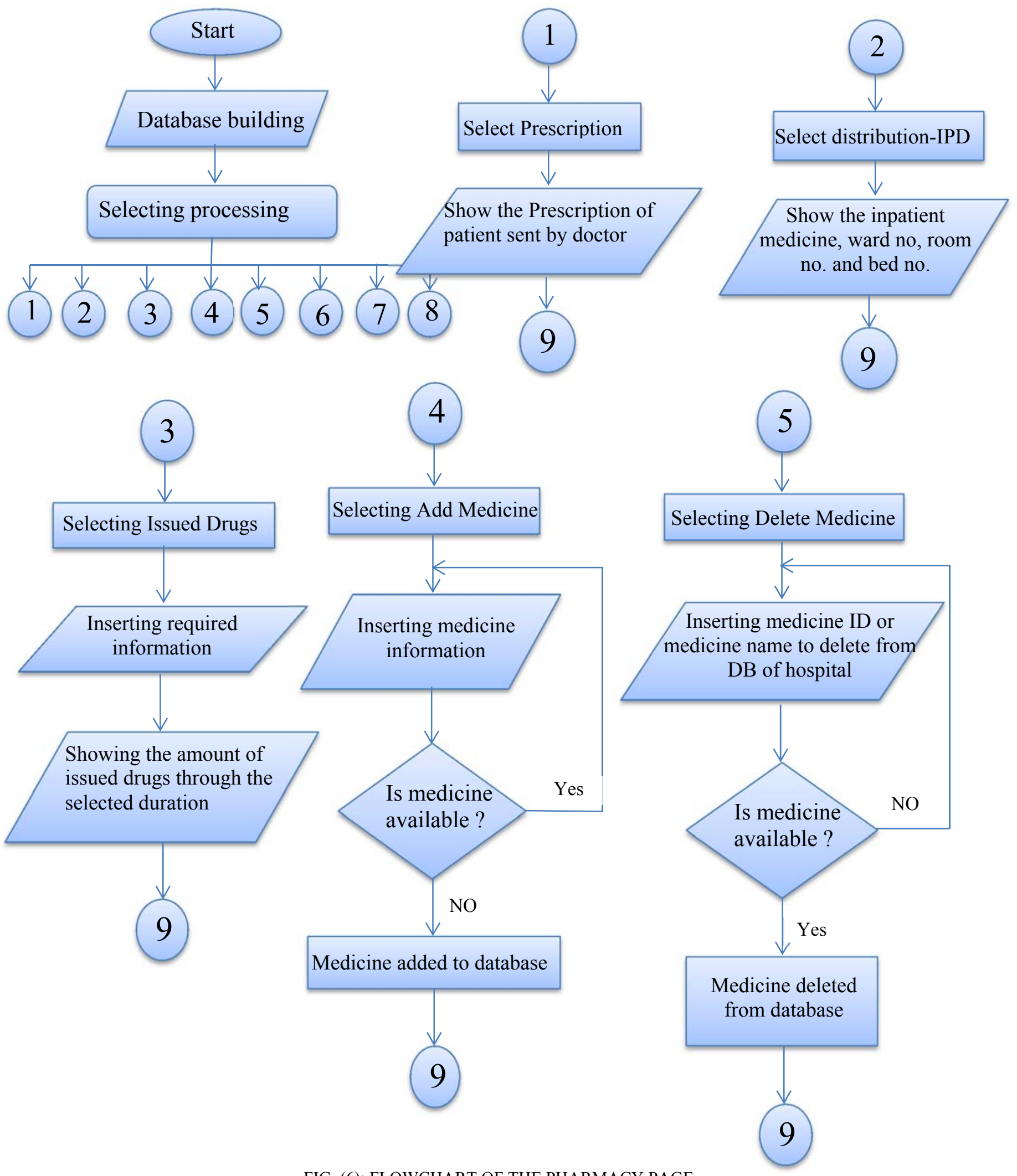

FIG. (6): FLOWCHART OF THE PHARMACY PAGE 


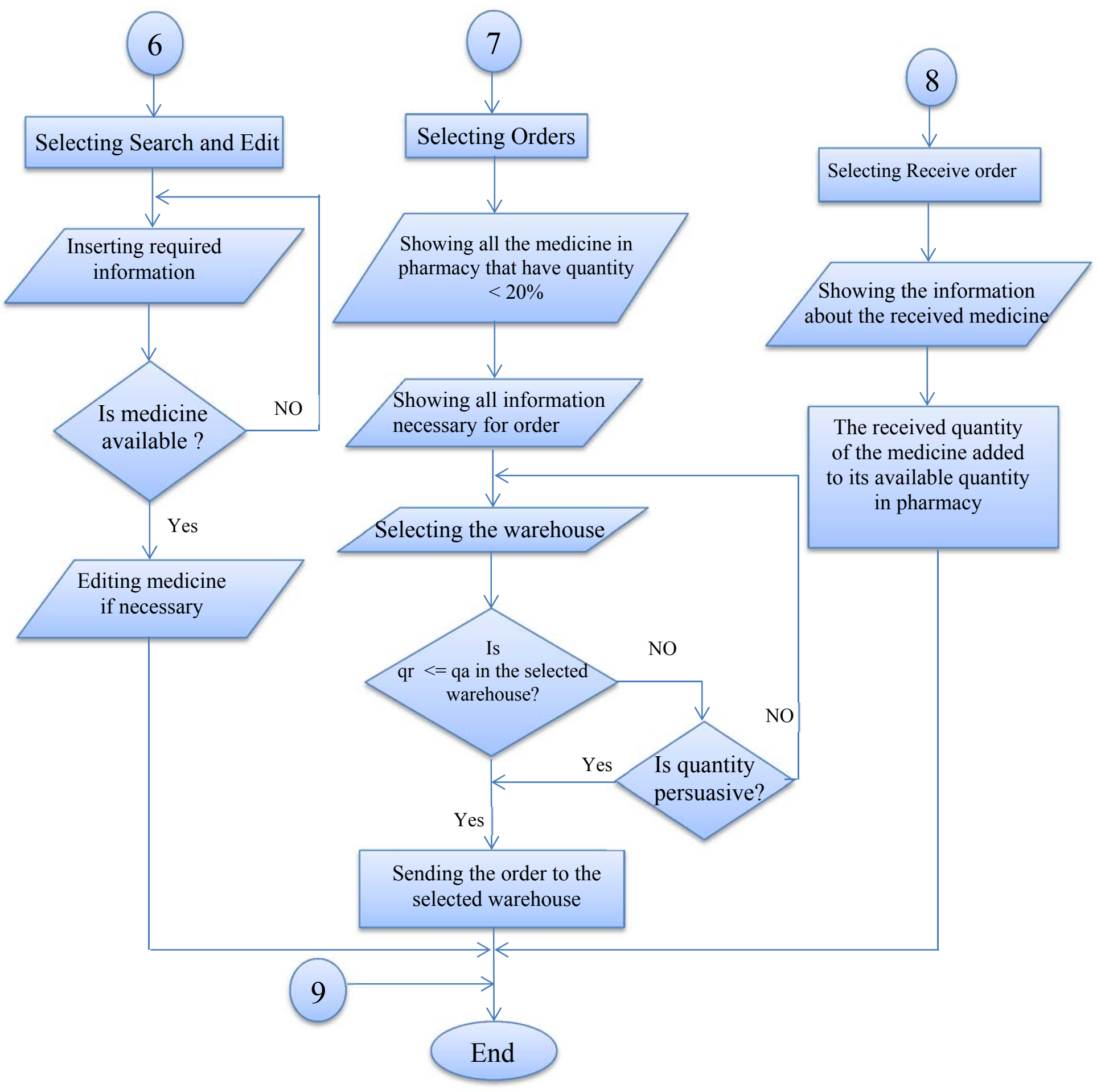

FIG. (6): CONTINUED 


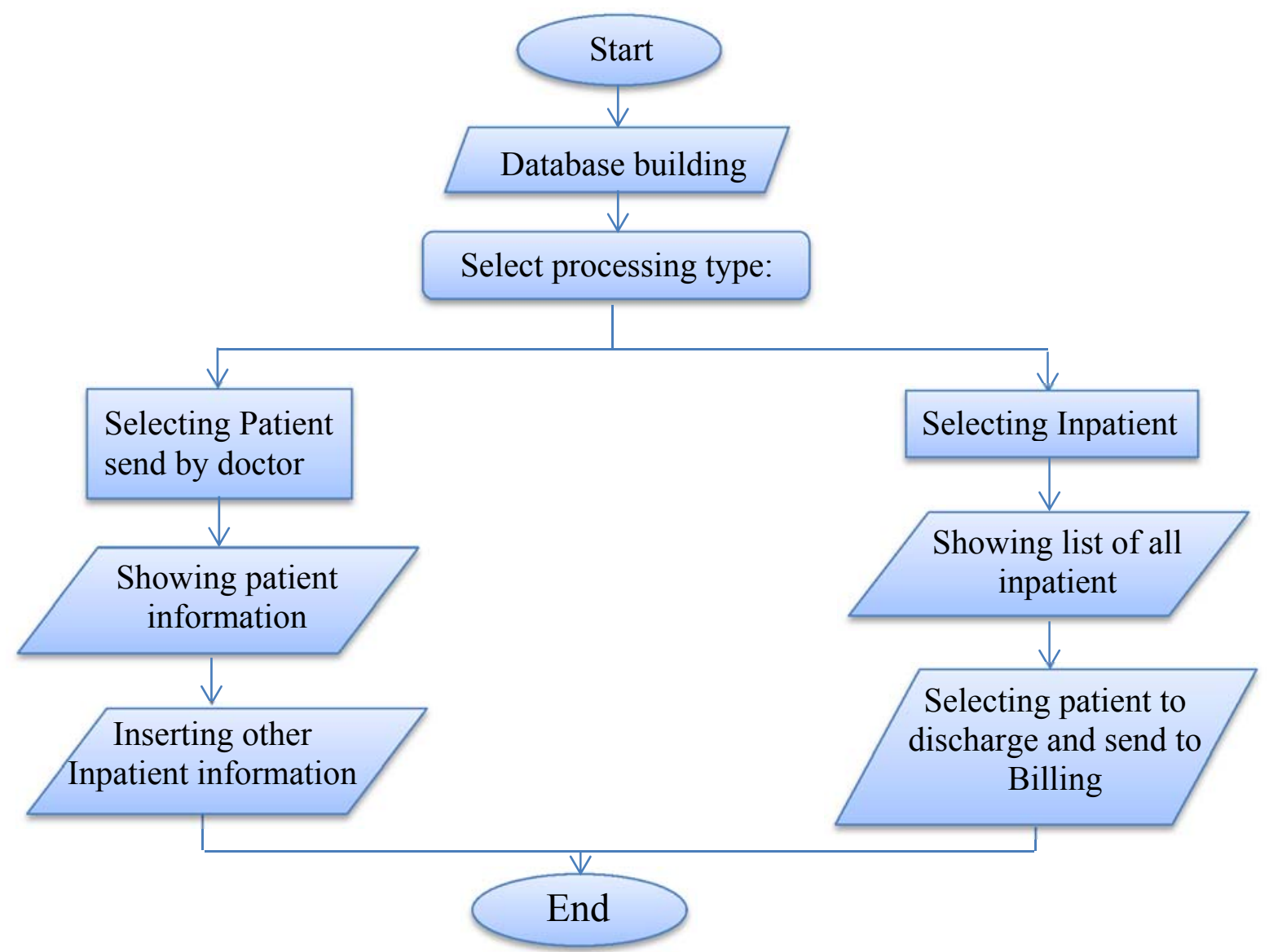

FIG. (7): FLOWCHART OF THE IPD PAGE

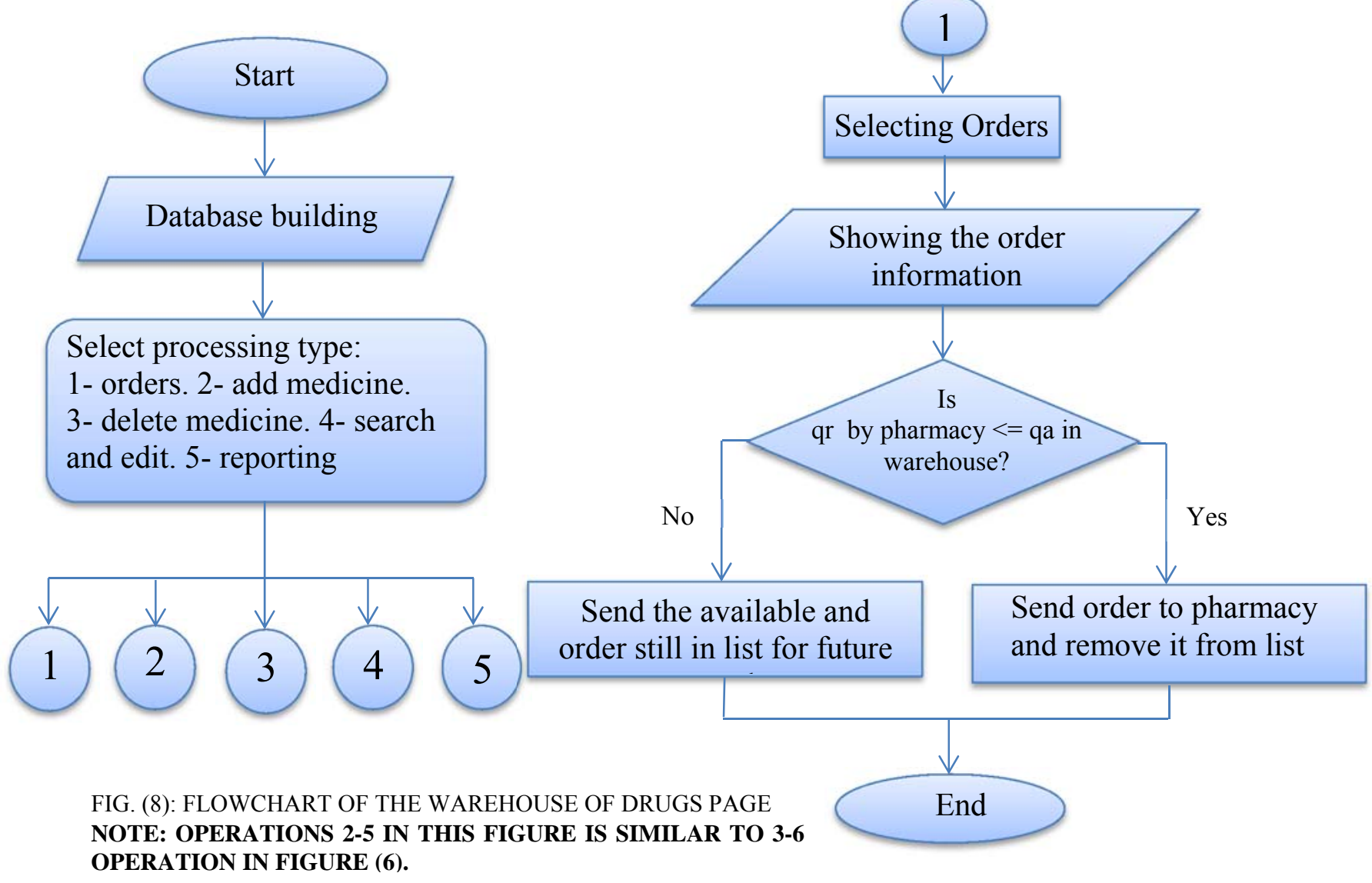




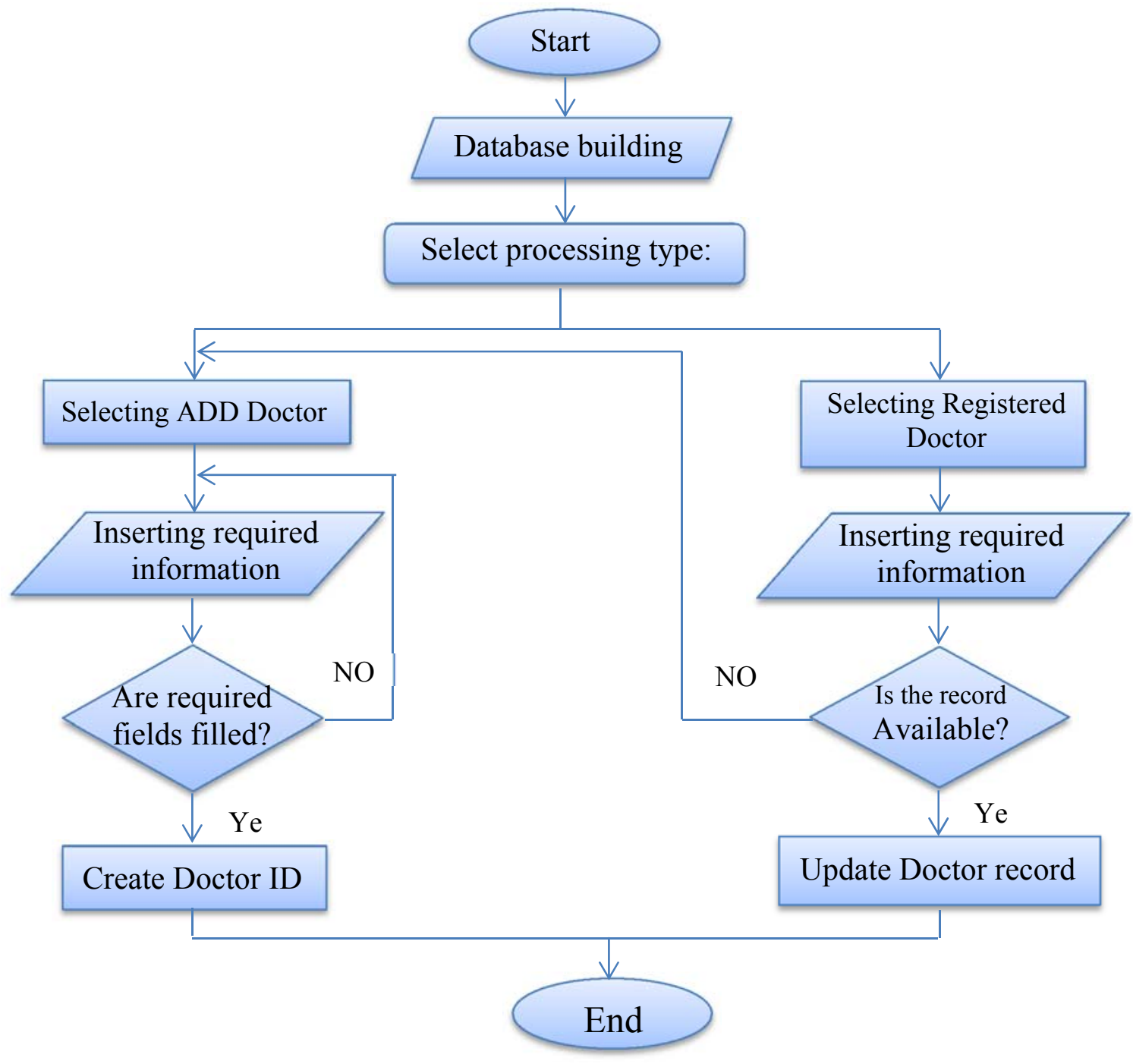

FIG. (9): FLOWCHART OF STAFF REGISTRATION PAGE.

\section{DATABASE BUILDING}

In this paper, the database has been built utilizing MySQL[9], [10]. According to the case study, two hospitals (Mergan in Babylon and Ibn-Alnafees in Baghdad) have been considered, the "mergan_db" database contains all tables related to Mergan hospital while the"nafees_db" includes all tables related to Ibn-Alnafees hospital. In addition, the"hospital" database includes only the patient's information that allow the patients to access their information from anywhere throw website and allows the two hospitals to access patient information.

One of tables in "mergan_db" database for patient information called "patient" table. The "patient" table includes 18 columns as shown in Fig. (10). It should be noted that this figure is not cover the whole table due to the size limit.

Other tables include "prescription" table for prescriptions sent form doctor to pharmacy, the "medicine" table for all medicine in the pharmacy of hospital, the "radiology" table for requests sent by doctor to radiology, the "lab" table includes tests requested by doctors for a patient, the "staff_reg" table includes the information of staff in hospital, the "doctor_reg" table contains doctors information, the "in_patient" table is used for inpatient information, the "blood_test" table contains the results of tests send from laboratory to doctor, and other tables required for the proposed system. 
It is highlighted that the limited number of pages restrict us from showing all tables. Therefore, the table "patient" has been taken as an example.

\begin{tabular}{|c|c|c|c|c|c|c|c|c|c|c|c|}
\hline hospital & patient_id & D_first_name & P_mid_name & P_third_name & P_sir_name & age & marital_status & patient_add & tele_no & patient_pass & gender \\
\hline Mergan & $117584 c 6 c 123631 a$ & avass & mahmood & ather & atjoun & 18 & single & & 07812665430 & 1234 & \\
\hline Mergan & 133584 c6 case 2185 & firas & asaad & & mamory & 33 & married & & & 4321 & male \\
\hline Mergan & $227584 c 6001883$ te & sara & adnan & & atjoun & 27 & single & & & 4567 & temate \\
\hline Mergan & $160584 c 503 a d c 184$ & saleem & mahmood & abdali & alrubajee & 60 & married & & 07703486210 & 0987 & male \\
\hline Mergan & $130585 \mathrm{~d} 272 \mathrm{e} 4 / 43 t$ & wesam & ahmed & ameer & atj,bun & 30 & married & hilla & 07812325430 & 22331 & male \\
\hline Mergan & $240585 d 2826 \mathrm{~b} 3093$ & ahlam & abass & adnan & tmimi & 40 & married & & & 4444 & femate \\
\hline $\begin{array}{l}\text { IDn } \\
\text { Ad-natees }\end{array}$ & $122585 \mathrm{~d} 28 \mathrm{c} 1 \mathrm{c} 1814$ & ayad & abdulaa & & atrubajee & 22 & single & & & 4433 & male \\
\hline $\begin{array}{l}\text { Ibn } \\
\text { AN-natees }\end{array}$ & $223585 d 28$ Вае $99 \mathrm{c}$ & fatema & hatem & & alajely & 23 & single & & & 2233 & female \\
\hline $\begin{array}{l}\text { Ibn } \\
\text { Ad-natees }\end{array}$ & $240585 d 292777065$ & salma & abdali & & atrubajee & 40 & married & & & 12345 & temate \\
\hline $\begin{array}{l}\text { Ibn } \\
\text { A-natees }\end{array}$ & $137585 d 2957 \mathrm{da3cd}$ & waseem & Whaled & & mamory & 37 & married & & & 55566 & male \\
\hline $\begin{array}{l}\text { Ion } \\
\text { N-natees }\end{array}$ & $143585029968 \mathrm{e} 203$ & rami & samit & & atsutani & 43 & mamed & & & 3344 & male \\
\hline Mergan & 150585d2a91deß3a & muslim & abdali & & alrubayee & 50 & married & & & 3344 & male \\
\hline $\begin{array}{l}\text { Ibn } \\
\text { Ad-natees }\end{array}$ & $153585 d 2 a b 7 d 6127$ & mohammed & rachi & & a!jburi & 53 & married & & & 4455 & male \\
\hline Ibn & $170585 d 2$ зе 13728 a & salman & raheem & & tmimi & 70 & married & & & 2233 & male \\
\hline
\end{tabular}

FIG. (10): PATIENT TABLE.

\section{WEBPAGE DESIGN}

The GUI based webpage design of the proposed system is performed using HTML and CSS environments. Fig. (11) shows the home page of the whole system which contains the login to all other parts of the system. Each user has his/her own identification number (ID) and password to login to a suitable page and according to his/her work type. The home page also contains information about the related hospitals, and the visitor can search about the doctors by using the doctor name or by doctor specialty to get a list of doctors and their information includes attendance days, telephone number, email and other necessary information. Two hospitals (Mergan and Ibn-Alnafis) have been considered in this system.

When the patient visits the website and fills his/her own required information in the login form, the patient page shows all the past records of patient concerning prescriptions, reports, tests, and radiology, means the patient can display his/her medical record from anywhere and at any time. In addition, the visitor can register to the system as a patient by click on New Registration button at home page and fill the form with required information. 


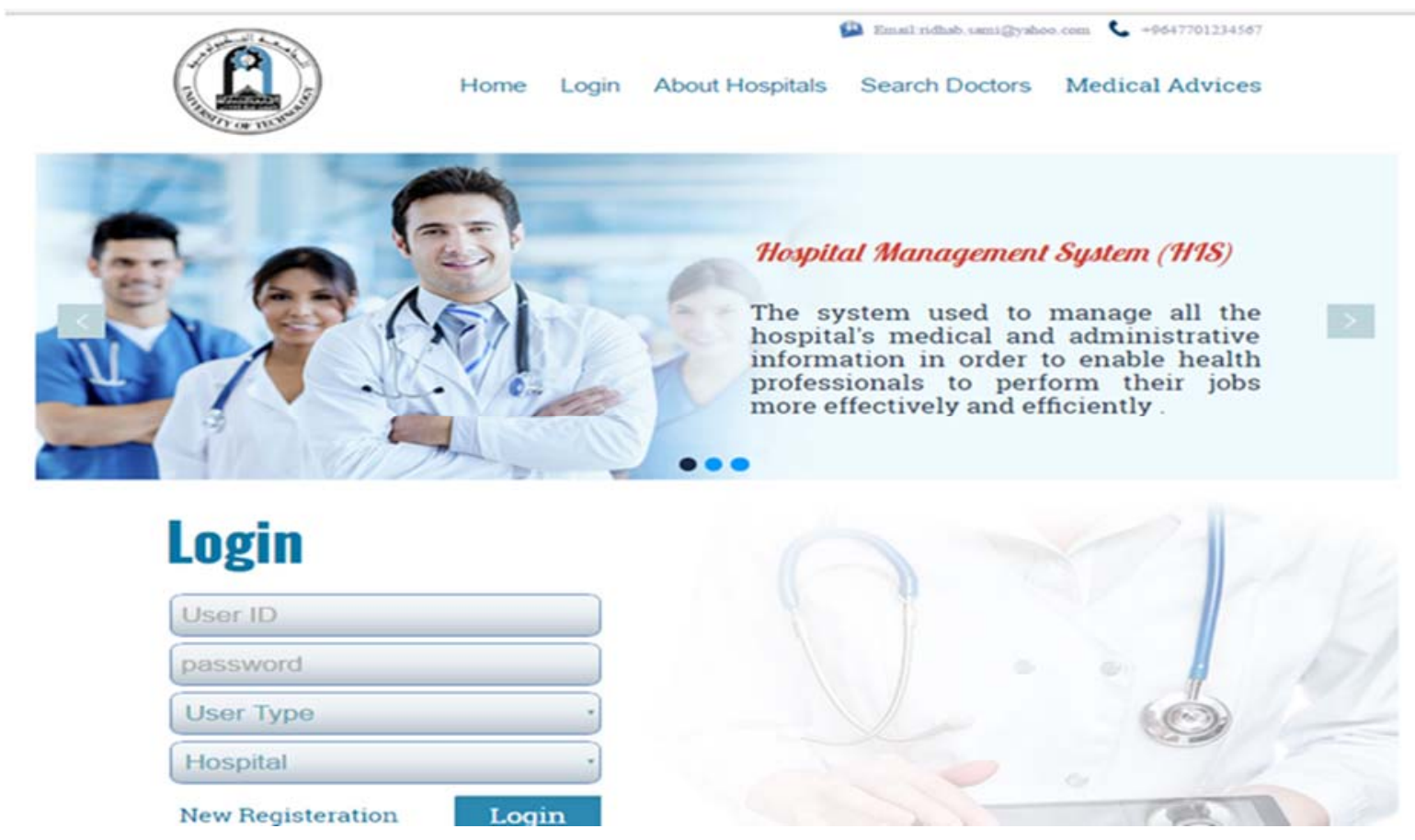

FIG. (11): HOME PAGE.

Fig. (12) shows the patient registration page. When the patient visits the hospital for the first time, the registration employee fills the appeared form with the required information. The ID is generated for the patient as a unique number for long term time period. The patient ID consists of series numbers represents the sex, age, and serial number of the patient. This is to prevent any duplication in future. It is important to note that the fields with (*) must be filled.

Registeration

\section{Add Patient Registered Patient}

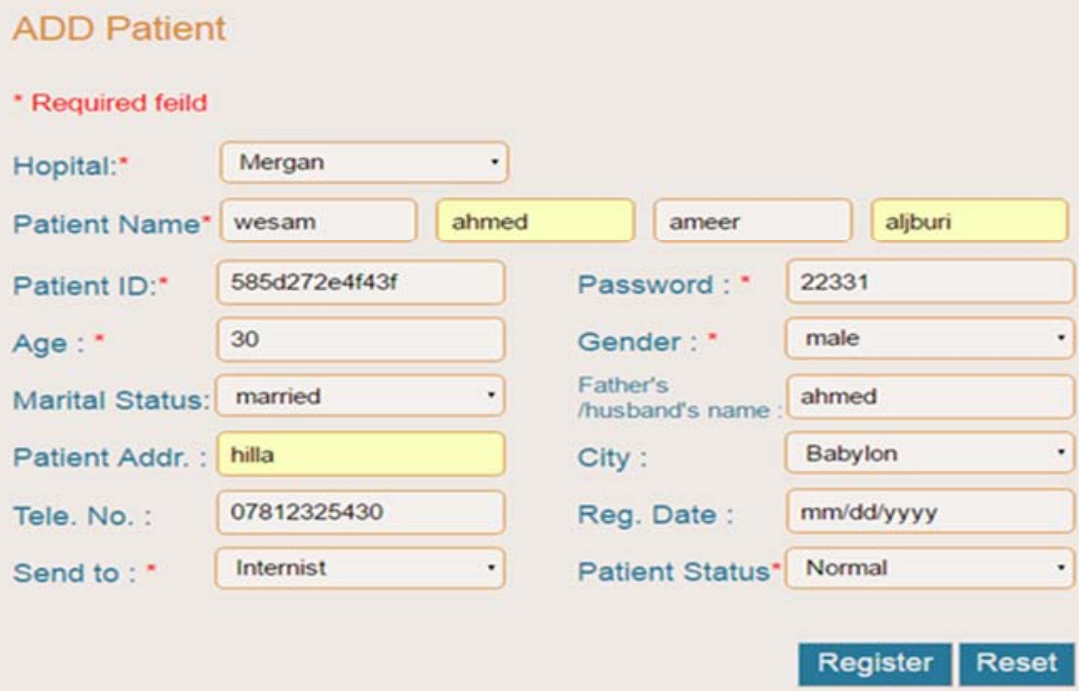

FIG (12): ADD PATIENT PAGE. 
Fig. (13) shows the case of the patient is already registered previously. The employee searches for him/her using the ID or patient name. After finding the patient, the related information can be updated easily and sent to the doctor after paying the billing fees for consultation.

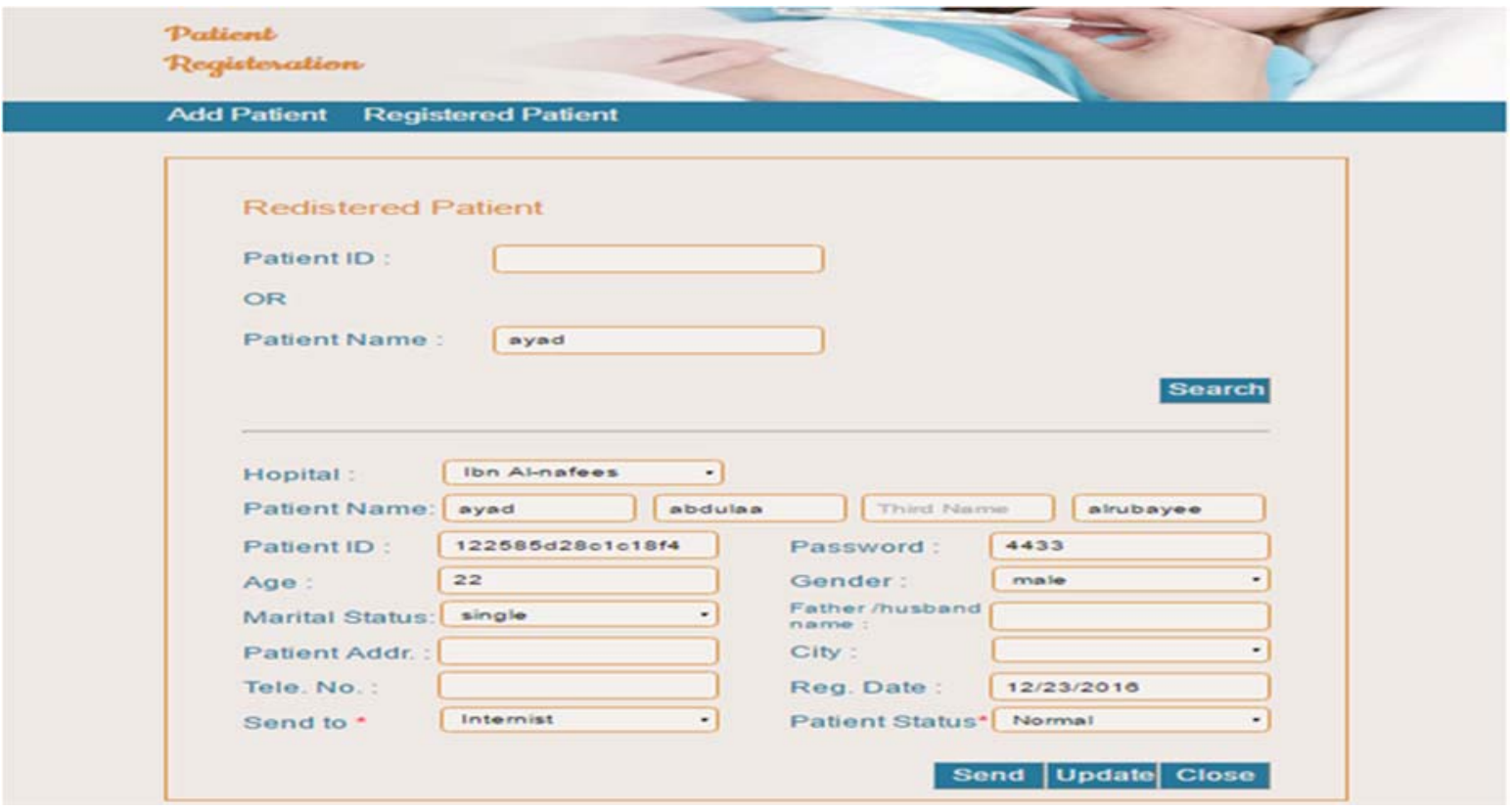

FIG. (13): REGISTERED PATIENT PAGE.

Fig. (14), shown the Billing page consists of Consultation Bill, Patient Bill and IPD Bill. These three options are managed by receiving the requested fees from different department of the hospital, such as doctors and then asking the patient to pay. After paying the required fees, the name of patients appear at the destination for completing the required tests, such as laboratories and radiology.

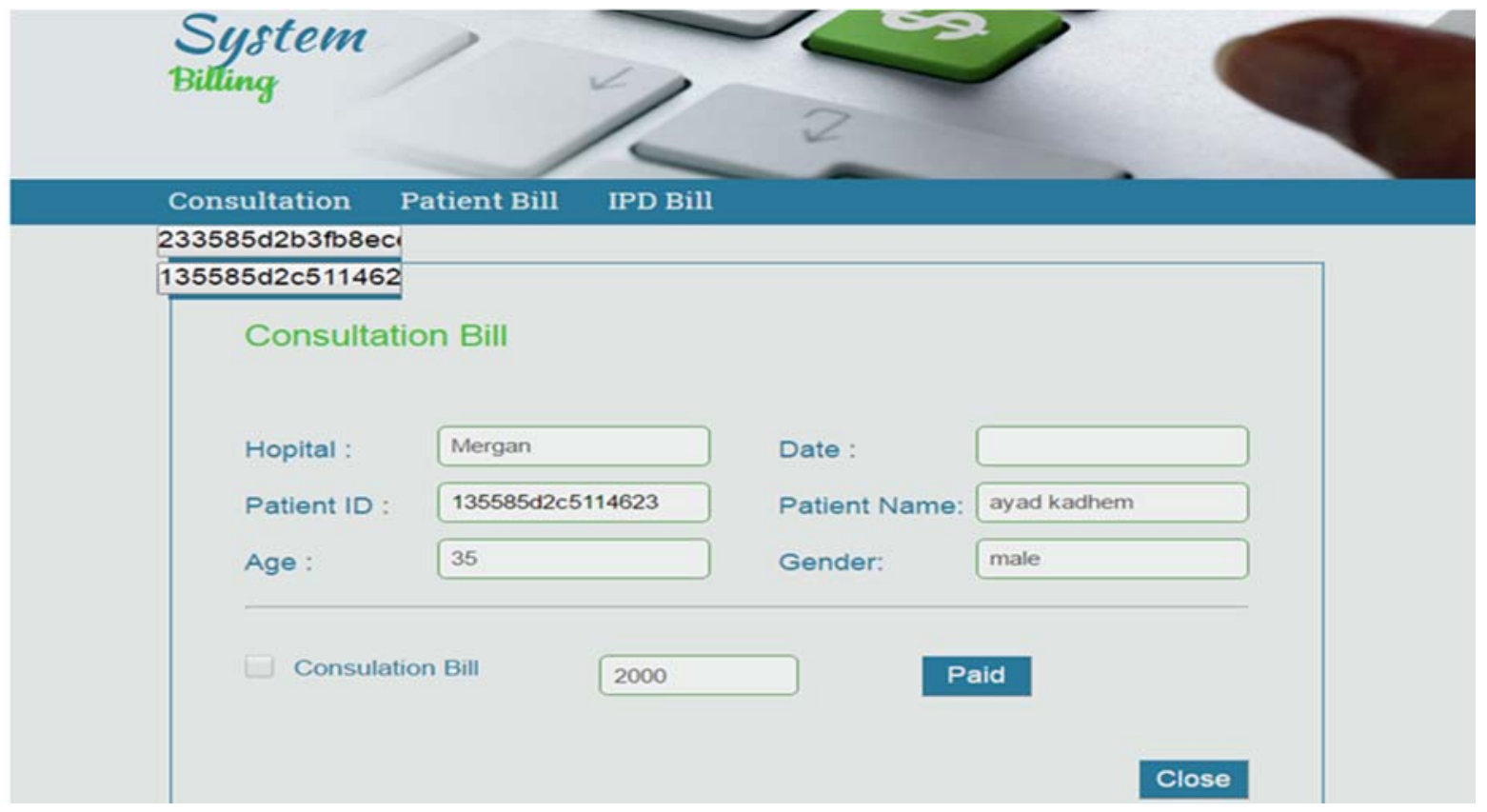

FIG. (14): BILLING PAGE.

Fig. (15), illustrates the doctor page. All registered patients appeared at this page for consultation as a list. When the doctor selects the patient ID from the list, whole information story of the patient is 
shown. The doctor can issue a prescription or send the patient to test or radiology if required. The patient ID still in the list until the doctor click on finish/remove from list button.

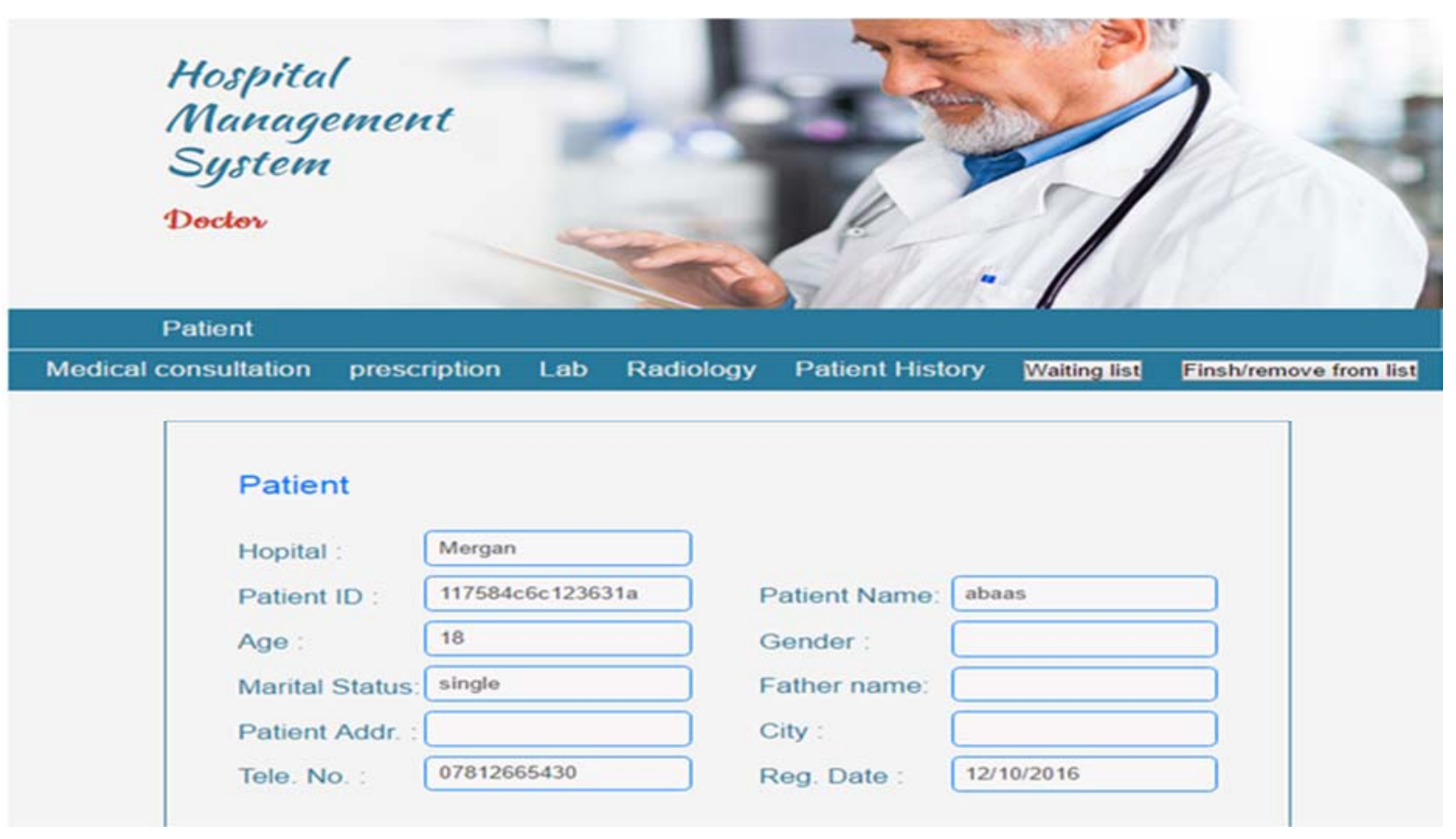

FIG. (15): DOCTOR PAGE.

Throughout the consultation process, the doctor can write his notes related to the patient in terms of genetic diseases or expected future diseases that help the doctors in the future. Moreover, there is a patient's history in this page, which allows the doctor to see all the past record of patient concerning prescriptions, reports, tests, and radiology. In addition, this page includes a replay list from laboratory results and reports showing.

\section{RESULTS}

As mentioned earlier, the database of the system has been built using MySQL environment, while the web pages have been designed using HTML, CSS and PHP languages. The proposed system is evaluated by taking different case studies in terms of applying the numerous actions to verify the reliability and validity of it. In the next sub-sections, the case studies consider some of the actions of the proposed system as we cannot cover all the activities of the system due to limited size of paper.

\section{A. Case Study One:}

The first case study starts from the laboratory form at the doctor page, who sends a request to the laboratory for performing a group of required tests as shown in Fig. (16). The patient's information is appeared in this form including the name and ID in addition to the required test types. Moreover, the test in this case is free, therefore there is no need for paying any bill. 


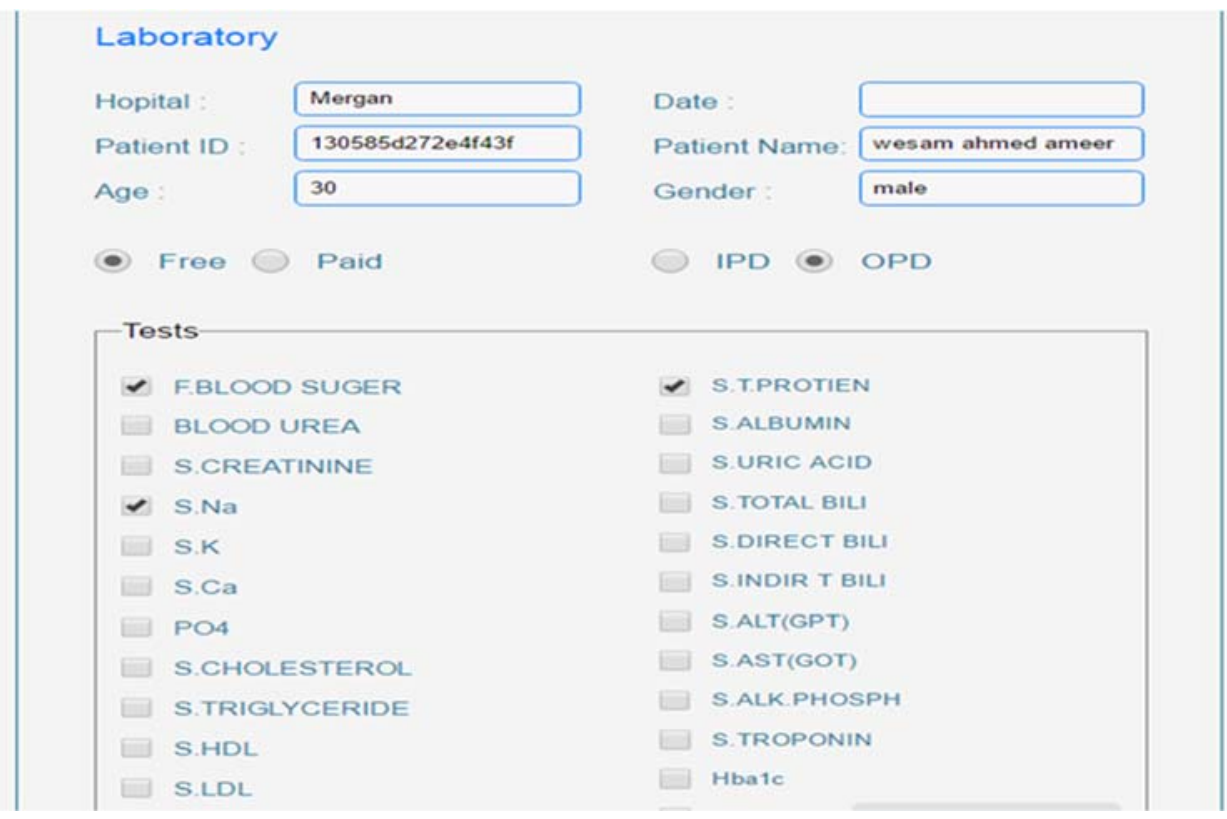

FIG. (16): LAB FORM ON DOCTOR PAGE.

Fig. (17) shows the Laboratory page that received the doctor's request regarding such patient. It is clearly shown that this page includes the group of tests and the laboratory should obtain the results to be sent back to the same doctor. The laboratory staff fill the obtained results in the form of results page shown on Fig. (18).

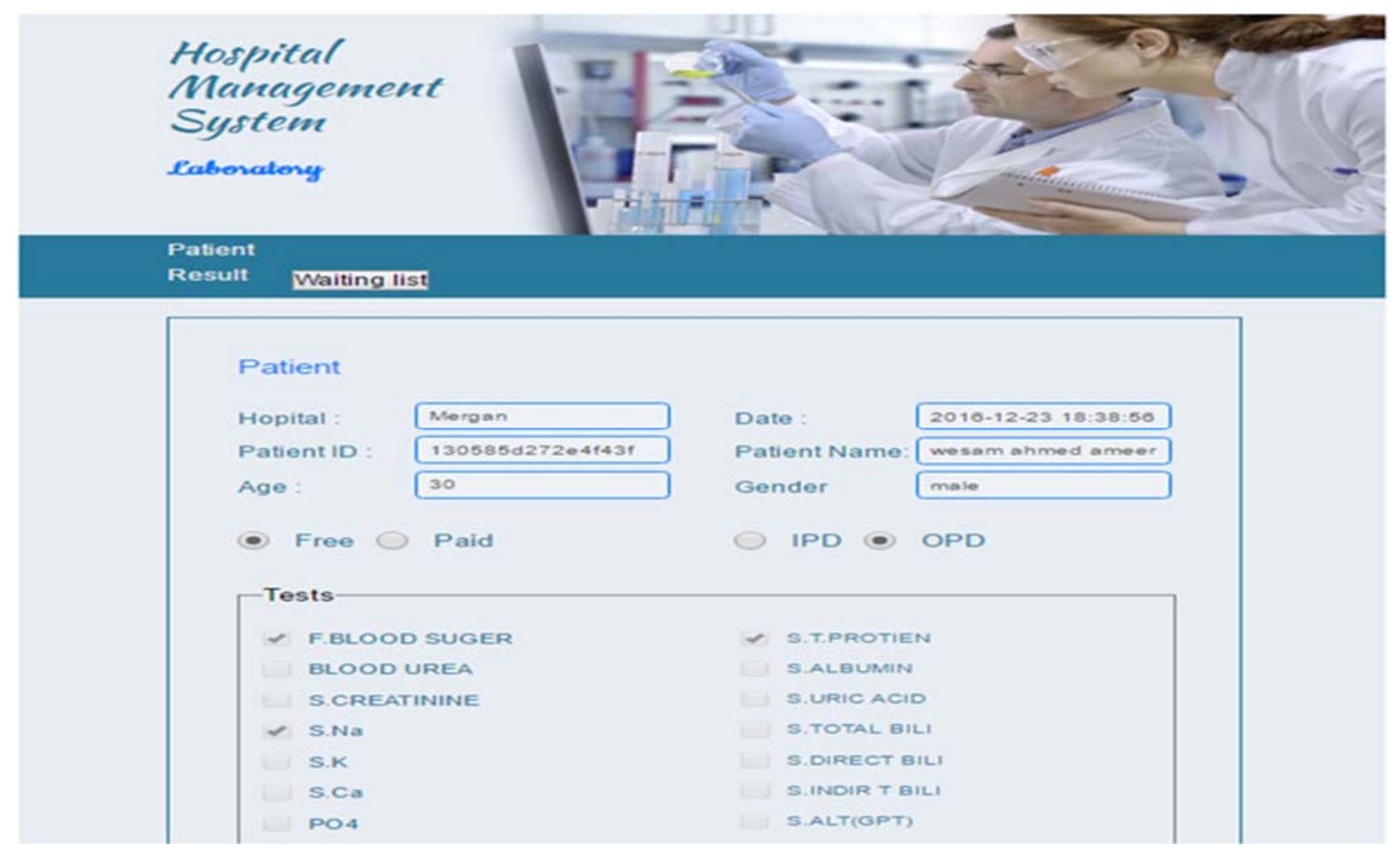

FIG. (17): LABORATORY PAGE. 


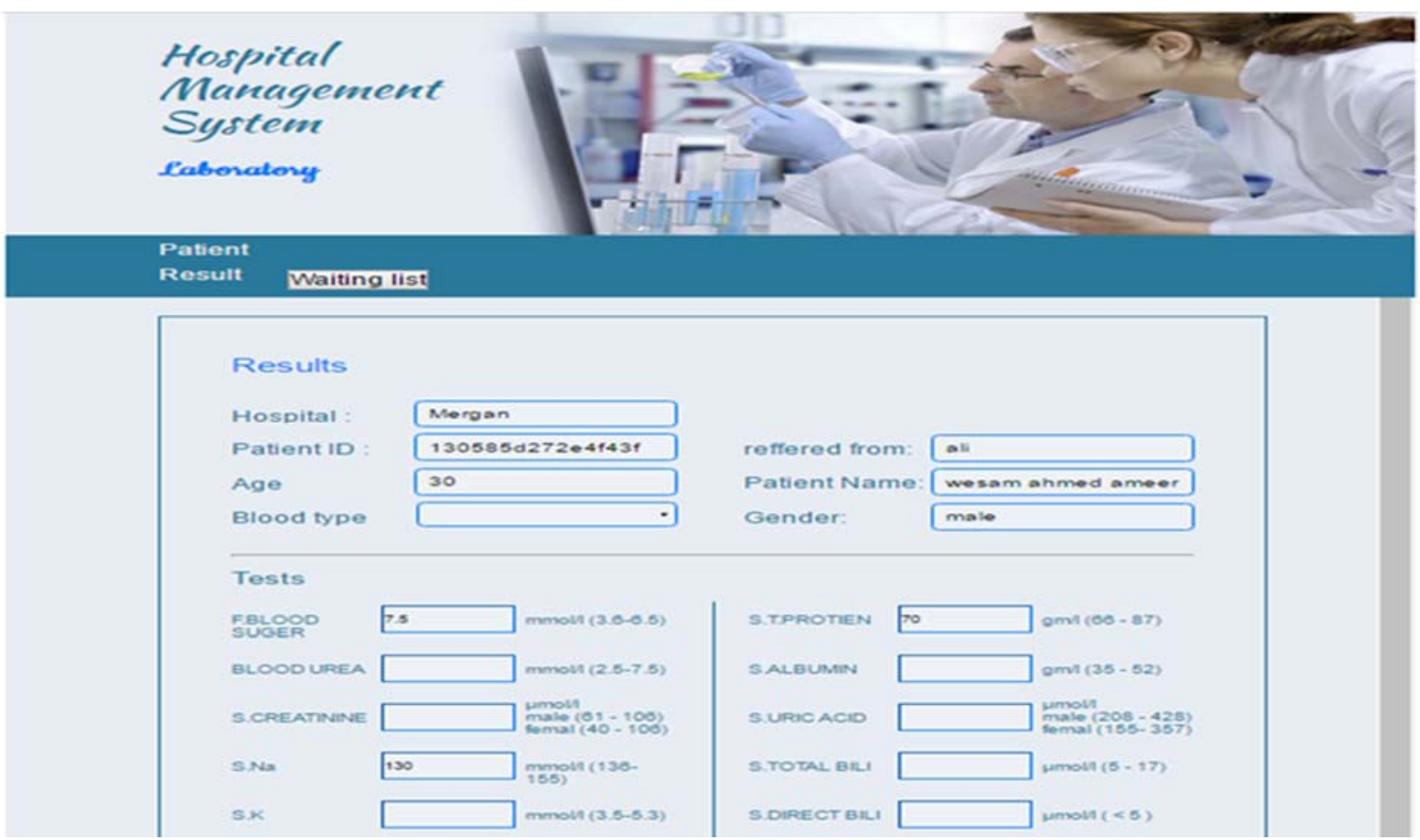

FIG. (18): RESULT IN LABORATORY PAGE.

Fig. (19) shows the laboratory results appeared in doctor page. His page shows the results that need attention by doctor as they are out of normal range. These types of results are appeared in red color.

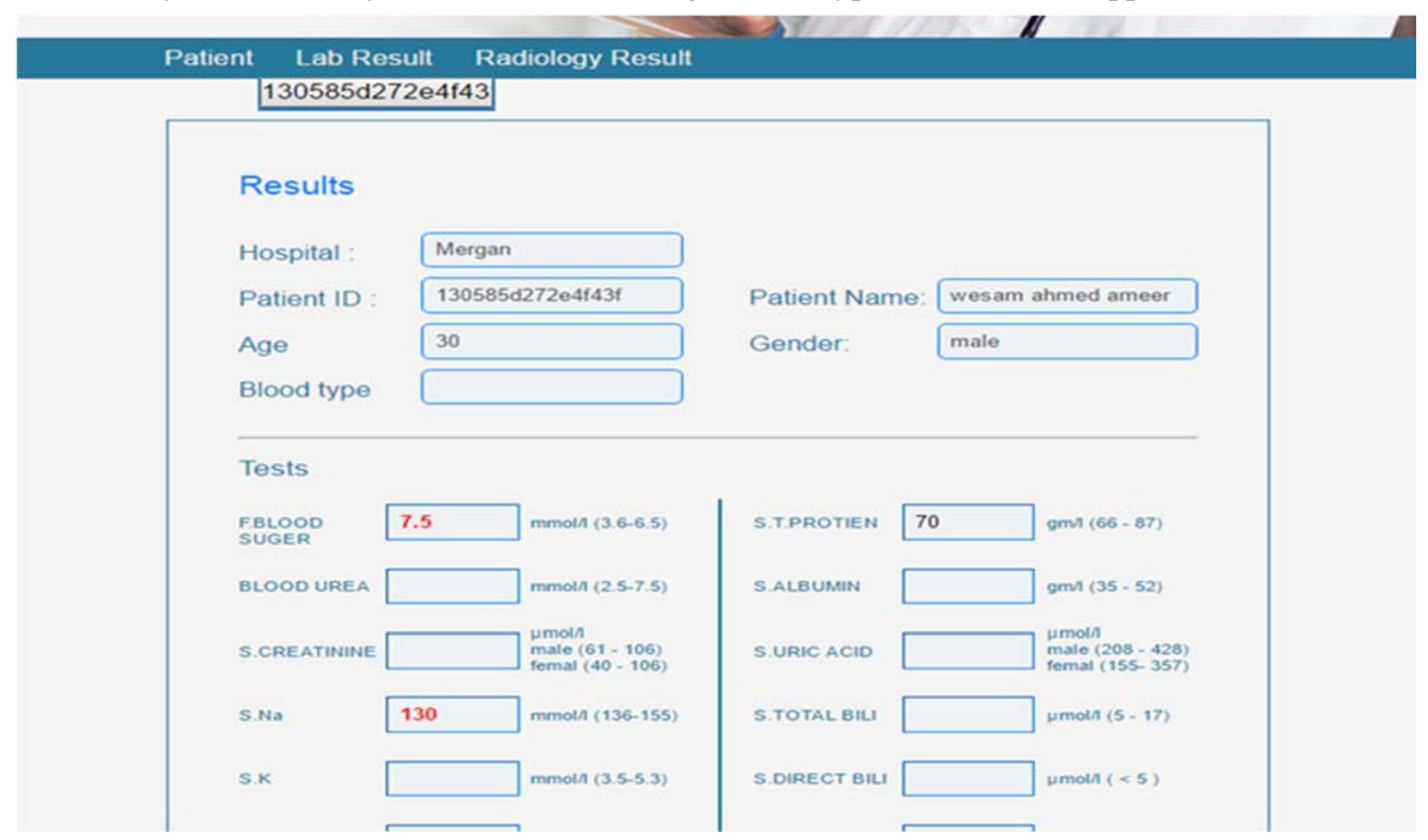

FIG. (19): LABORATORY RESULTS APPEARED IN THE DOCTOR PAGE.

\section{B.Case Study Two:}

Case study two considers the IPD patient page with the billing page. Fig. (20) shows the IPD page. When the patient needs to be admitted into the hospital, then the doctor sends the patient to IPD. The 
IPD employee click on the patient ID in the list, then the patient information is shown. The employee allocates an appropriate room and bed number to the patient and the system reduces the available beds in hospital by one as shown in Fig. (21).

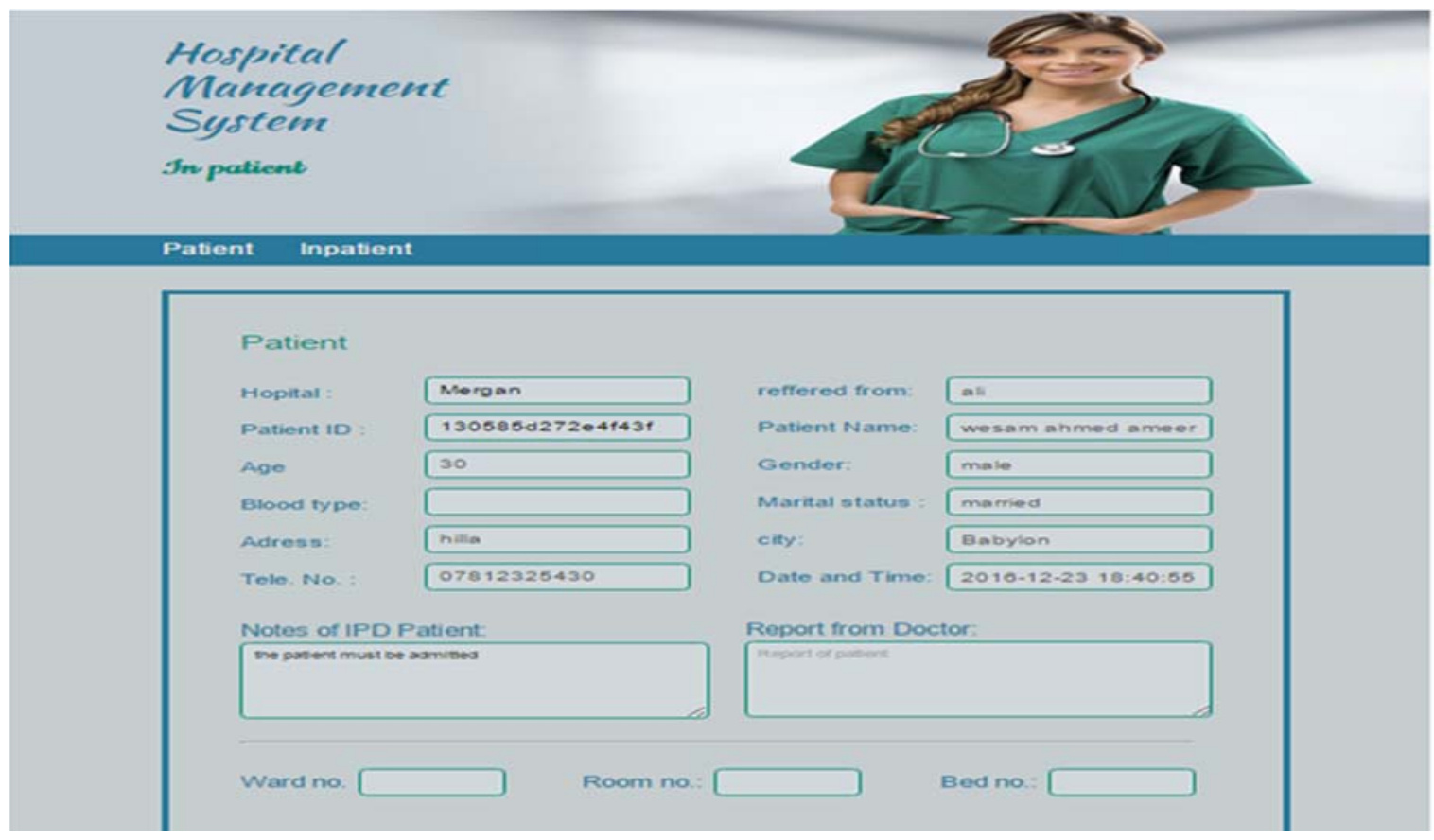

FIG. (20): IPD PAGE.

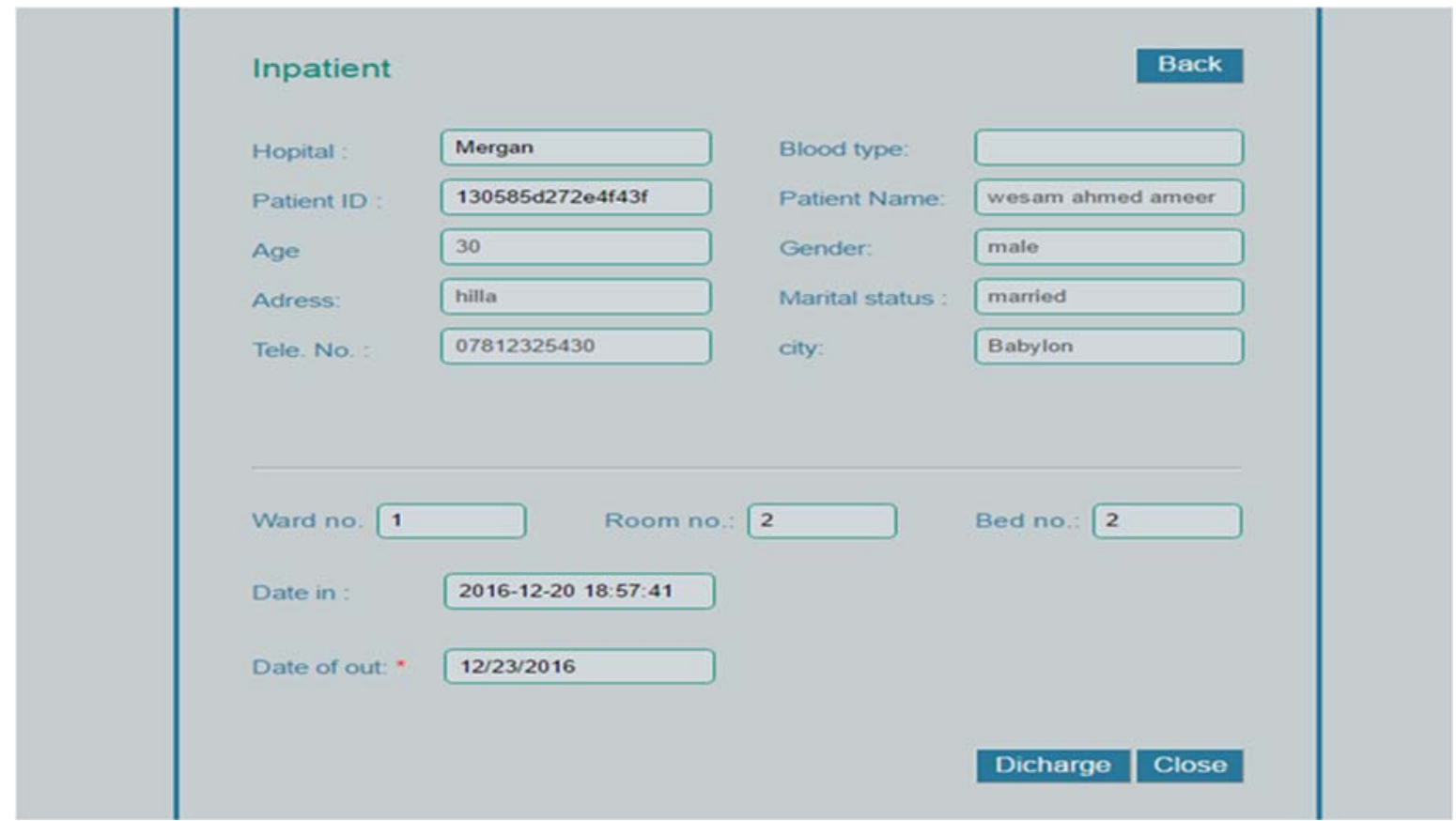

FIG. (21): INPATIENT ON IPD PAGE.

In addition, the patient that have been decided to be discharged is selected from the list by clicking the discharge button as explain in Fig. (21). Then all information of a patient is sent to the billing page for paying the required bill. 
Fig. (22) shows the billing page that includes a requested bill sent from IPD after discharging the patient based on the number of staying days, medicines, .., etc.

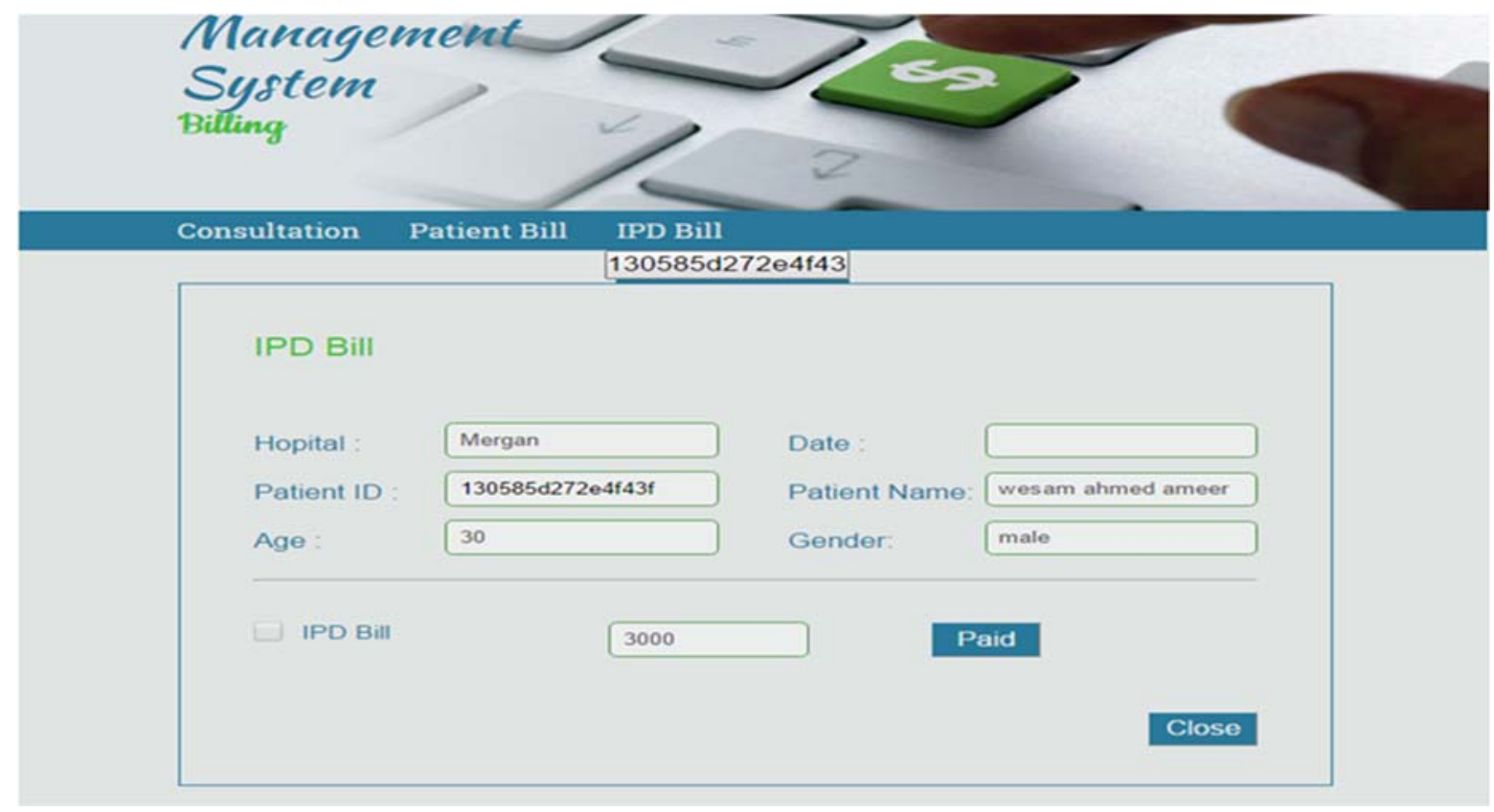

FIG. (22): IPD BILL IN THE BILLING PAGE.

From the obtained results, we can see the proposed system is easy to use with a high degree of flexibility and efficiency. Furthermore, the proposed system provides security where each user to the system has its own username and password. It is an efficient alternative to paper-based archiving system.

\section{CONCLUSIONS:}

This paper presented a proposed web based e-hospital management system following the steps of HMS roles. This system included two main parts: database and webpage GUI. All information is stored in the database for being used by the doctors, patients and other users of the system. In order to ease the using of the proposed system, GUI based webpages have been designed for two reasons. Firstly, to give globalist to the system in terms of accessing and secondly the using of the system by numerous hospitals. In addition, the proposed system offed an efficient links between the department of hospital, in which different types of data can be send over, such as images and videos. There were several advantages of using the system which include: easy access to required data, the unauthorized users cannot access to patient information or to doctor page, pharmacy page, or other pages of the system, data can be inserted/updated/deleted easily, provide user friendly interface, enhancement of patient care quality, saving paper work, provides monitoring of drug usage, time saving and increase time the doctor or nurse can spend with patient, the system supports the decision making at the hospital, easy to use and reduced medication mistakes and errors caused by handwriting. There were several barriers in terms of human and financial obstacles that might stand against the evolution of the system and change the hospital system from paper to completely paperless system, the problem of lack in providing technical support for this type of systems through and after their implementation, the costs of training the users on how can manage this type of systems, low acceptance Level. The database system was built using MySQL, while webpages were designed using PHP, HTML and CSS environments. The proposed system was tested in different categories considered as case studies. The obtained results showed a high performance and accuracy of the proposed system. 


\section{REFERENCES}

[1] Olamide O., Adedayo E. and Abiodun O.. "Design and Implementation of Hospital Management System Using Java " IOSR Journal of Mobile Computing \& Application, 2015.

[2] Burns T., Catty J., Dash M., Roberts C., Lockwood, A., and Marshall M. "Use of intensive case management to reduce time in hospital in people with severe mental illness: systematic review and meta-regression", BMJ, 2007.

[3] Edwards Marie and Jackie Moczygemba. "Reducing medical errors through better documentation", The health care manager, 2004.

[4] Mutemwa Richard I. "HMIS and decision-making in Zambia: re-thinking information solutions for district health management in decentralized health systems,", Health Policy and Planning, 2006.

[5] Kart F., Miao G., Moser L. E., and Melliar-Smith P. M. "A distributed e-healthcare system based on the service oriented architecture." IEEE International Conference on Services Computing (SCC 2007). IEEE, 2007.

[6] Hasan Jahidul. "Integrated Hospital Information System (HIS) Special focus on BIRDEM Hospital (600 Beds)." (2013).

[7] Jayawardena A. S.. "The Electronic Hospital Information System Implemented at the District General Hospital Trincomalee-An Experience of Business Process Reengineering." Journal of Community Medicine \& Health Education 2014 (2014).

[8] Khalifa Mohamed. "Barriers to health information systems and electronic medical records implementation. A field study of Saudi Arabian hospitals." Procedia Computer Science 21 (2013): 335-342.

[9] Hoffer, Jeffrey A. "Modern Database Management", Tenth edition, Pearson Education India, 1999.

[10] "why-mysql", https://www.mysql.com/why-mysql/topreasons.html. Accessed 25122016 